\title{
SMALL AREA ESTIMATION DENGAN PENDEKATAN EMPIRICAL BAYES BERBASIS MODEL BETA-BINOMIAL UNTUK MENDUGA ANGKA PENGANGGURAN DI SUMATERA BARAT
}

\author{
NURMAYLINA ZAJA, HAZMIRA YOZZA, FERRA YANUAR \\ Program Studi S1 Matematika, \\ Fakultas Matematika dan Ilmu Pengetahuan Alam, Universitas Andalas, \\ Kampus UNAND Limau Manis Padang, Indonesia. \\ email : ainzaaja@gmail.com
}

Diterima 9 Maret $2019 \quad$ Direvisi 7 April $2019 \quad$ Dipublikasikan 7 Mei 2019

\begin{abstract}
Abstrak. Penelitian ini bertujuan untuk menduga angka pengangguran di kabupaten/kota di Sumatea Barat dengan metode Small Area Estimation dengan pendekatan Empirical Bayes berbasis model Beta-Binomial. hal ini dilakukan karena informasi yang dikeluarkan oleh Badan pusat Statistik (BPS) tahun 2016 hanya angka pengangguran tingkat provinsi dan tidak tersedia data untuk tingkat kabupaten/kota. Penelitian ini menggunakan data BPS, yaitu jumlah pengangguran dan jumlah angkatan kerja di kabupaten/kota di Sumatera Barat. Penelitian ini menghasilkan nilai dugaan angka pengangguran kabupaten/kota di Sumatera Barat dengan metode langsung dan metode Empirical Bayes. Dengan demikian dapat disimpulkan bahwa penduga menggunakan metode Empirical Bayes lebih baik dari metode langsung.
\end{abstract}

Kata Kunci: Small Area Estimation, Empirical Bayes, Angka Pengangguran

\section{Pendahuluan}

Permasalahan dalam berbagai pendugaan indikator ketenagakerjaan untuk tingkat kabupaten/kota adalah ketidakcukupan ukuran contoh. Jika penghitungan indikator ketenagakerjaan untuk tingkat kabupaten/kota dilakukan secara langsung tanpa adanya penambahan contoh, maka disebut sebagai pendugaan langsung. Pendugaan secara langsung yang dilakukan pada area kecil akan menghasilkan suatu nilai ragam yang besar jika contoh yang diambil berasal dari survei yang dirancang untuk skala besar. Hal ini disebabkan oleh kecilnya ukuran contoh yang terambil pada suatu area tersebut serta dipaksakan untuk mendapatkan penduga area kecilnya. Model pendugaan area kecil merupakan suatu alternatif yang dapat digunakan untuk menduga parameter pada suatu area ketika ukuran contoh area tersebut terlalu kecil. Kejadian pengangguran merupakan data biner, dimana kejadian tersebut hanya terjadi menganggur atau tidak menganggur. Dari penjelasan di atas, sangat menarik untuk dipelajari aplikasi metode small area estimation dengan model Beta-Binomial dalam menduga angka pengangguran di tingkat Kabupaten di Sumatera Barat. 


\section{Pendugaan Parameter Sebaran Binomial}

Misalkan $Y_{i}$ adalah suatu peubah acak yang diasumsikan menyebar menurut sebaran Binomial, dengan $n$ banyak ulangan dan $\theta$ adalah peluang keberhasilan. Untuk menduga parameter $\theta$ dapat digunakan metode penduga kemungkinan maksimum dan metode Bayes.

\subsection{Penduga Kemungkinan Maksimum Sebaran Binomial}

Misalkan $X_{i}$ adalah peubah acak yang bernilai 1 dan 0 . peubah $X_{i}$ diasumsikan memiliki sebaran Bernoulli dengan parameter $\theta$ atau ditulis $X_{i} \mid \theta \sim \operatorname{Bernoulli}(\theta)$ untuk $i=1,2, \cdots, n$ dengan fungsi kepekatan peluang

$$
f\left(X_{i} \mid \theta\right)=\theta^{x}(1-\theta)^{1-x_{i}}, X_{i}=0,1 .
$$

Selanjutnya didefinisikan $Y=\sum_{i=1}^{n} X_{i}$, adalah jumlah kejadian berhasil dari $n$ kali ulangan. Peubah acak $Y$ akan memiliki sebaran Binomial $(n, \theta)$ dengan fungsi kepekatan peluang [1]:

$$
f(y \mid \theta)=\left(\begin{array}{l}
n \\
y
\end{array}\right) \theta^{y}(1-\theta)^{n-y}, y=0,1, \cdots, n .
$$

Fungsi kemungkinan dari peubah acak $Y$ adalah [1]:

$$
L(\theta \mid y)=f(y \mid \theta)=\left(\begin{array}{l}
n \\
y
\end{array}\right) \theta^{y}(1-\theta)^{n-y} .
$$

Logaritma natural dari fungsi kemungkinan adalah sebagai berikut.

$$
l(\theta \mid y)=\ln \left(\begin{array}{l}
n \\
y
\end{array}\right)+y \ln (\theta)+(n-y) \ln (1-\theta) .
$$

Maksimum daril $l(\theta \mid y)$ diperoleh bila

$$
\begin{aligned}
\frac{\partial}{\partial \theta} l(\theta \mid y) & =0, \\
\frac{\partial}{\partial \theta} \ln \left(\left(\begin{array}{l}
n \\
y
\end{array}\right)+y \ln (\theta)+(n-y) \ln (1-\theta)\right) & =0, \\
\theta & =\frac{y}{n} .
\end{aligned}
$$

Jadi penduga kemungkinan maksimum bagi $\theta$ Jika $Y \sim B I N(n, \theta)$ adalah $\hat{\theta}=$ $\frac{y}{n}$, dengan $y$ adalah banyaknya keberhasilan dalam $n$ kali ulangan. Penduga ini merupakan penduga yang bersifat tak-bias karena nilai harapan dari penduga sama dengan parameternya [2], sebagaimana yang diperlihatkan oleh:

$$
E(\hat{\theta})=E\left(\frac{Y}{n}\right)=\frac{1}{n} E(Y)=\frac{1}{n} n \theta=\theta .
$$

dengan ragamnya, yaitu [2].

$$
\begin{aligned}
\operatorname{Var}(\hat{\theta}) & =\operatorname{Var}\left(\frac{Y}{n}\right)=\frac{1}{n^{2}} \operatorname{Var}(Y), \\
& =\frac{1}{n^{2}} n \theta(1-\theta), \\
& =\theta(1-\theta) .
\end{aligned}
$$


122 Nurmaylina Zaja dkk.

\subsection{Penduga Bayes Sebaran Binomial}

Misalkan $Y$ adalah suatu peubah acak diasumsikan menyebar menurut sebaran Binomial atau ditulis $Y \sim B I N(n, \theta)$ dengan $\theta$ adalah peluang keberhasilan. Diasumsikan juga bahwa peluang keberhasilan, $\theta$ tersebut menyebar menurut distribusi Beta atau ditulis $\theta \sim \operatorname{Beta}(\alpha, \beta), \alpha>0, \beta>0$, jadi fungsi kepekatan peluang (distribusi) prior bagi $\theta$ adalah

$$
f(\theta \mid \alpha, \beta)=\frac{1}{B(\alpha, \beta)} \theta^{\alpha-1}(1-\theta)^{\beta-1}, 0 \leq \theta \leq 1 .
$$

Berdasarkan definisi distribusi posterior yaitu [3]

$$
f(\theta \mid y)=\frac{f(\theta \mid y) f(\theta)}{f(y)} .
$$

Dari persamaan (2.1) dan (2.12) diperoleh fungsi kepekatan peluang bersama dari $Y$ dan $\theta$ adalah

$$
\begin{aligned}
f(y, \theta) & =f(y \mid \theta) f(\theta)=\left(\begin{array}{l}
n \\
y
\end{array}\right) \theta^{y}(1-\theta)^{n-y} \frac{1}{B(\alpha, \beta)} \theta^{\alpha-1}(1-\theta)^{\beta-1} \\
& =\left(\begin{array}{l}
n \\
y
\end{array}\right) \frac{1}{B(\alpha, \beta)} \theta^{y+\alpha-1}(1-\theta)^{n-y+\beta-1} .
\end{aligned}
$$

Fungsi kepekatan peluang marginal bagi $Y$ adalah

$$
\begin{aligned}
f(y) & =\int_{0}^{1} f(y, \theta) d \theta, \\
& =\left(\begin{array}{l}
n \\
y
\end{array}\right) \frac{1}{B(\alpha, \beta)} B(y+\alpha, n-y+\beta) .
\end{aligned}
$$

Dengan demikian distribusi posterior bagi $\theta$ adalah

$$
\begin{aligned}
f(\theta \mid y) & =\frac{\left(\begin{array}{l}
n \\
y
\end{array}\right) \frac{1}{B(\alpha, \beta)} \theta^{y+\alpha-1}(1-\theta)^{n-y+\beta-1}}{\left(\begin{array}{l}
n \\
y
\end{array}\right) \frac{1}{B(\alpha, \beta)} B(y+\alpha, n-y+\beta)}, \\
& =\frac{1}{B(\alpha, \beta)} B(y+\alpha, n-y+\beta) \theta^{y+\alpha-1}(1-\theta)^{n-y+\beta-1}
\end{aligned}
$$

Berdasarkan Persamaan (2.16) diperoleh $\theta \mid y \sim B(y+\alpha, n-y+\beta)$ yang memiliki mean sebagai berikut

$$
\begin{aligned}
E(\theta \mid y, \alpha, \beta) & =\int_{0}^{1} \theta \frac{\Gamma(n+\alpha+\beta)}{\Gamma(y+\alpha) \Gamma(n-y+\beta)} \theta^{y+\alpha-1}(1-\theta)^{n-y+\beta-1} d \theta \\
& =\frac{(y+\alpha)}{(n-y+\beta)}
\end{aligned}
$$

dan ragamnya adalah

$$
\operatorname{Var}(\theta \mid y, \alpha, \beta)=E\left(\theta^{2} \mid y, \alpha, \beta\right)-[(\theta \mid y, \alpha, \beta)]^{2}
$$


terlebih dahulu akan dicari $E\left(\theta^{2} \mid y, \alpha, \beta\right)$

$$
\begin{aligned}
E\left(\theta^{2} \mid y, \alpha, \beta\right) & =\int_{0}^{1} \theta^{2} \frac{\Gamma(n+\alpha+\beta)}{\Gamma(y+\alpha) \Gamma(n-y+\beta)} \theta^{y+\alpha-1}(1-\theta)^{n-y+\beta-1} d \theta, \\
& =\frac{(y+\alpha)(1+y+\alpha)}{(n-y+\beta)(1+n+\alpha+\beta)} .
\end{aligned}
$$

Sehingga diperoleh ragam sebagai berikut:

$$
\begin{aligned}
\operatorname{Var}(\theta \mid y, \alpha, \beta) & =E\left(\theta^{2} \mid y, \alpha, \beta\right)-[(\theta \mid y, \alpha, \beta)]^{2}, \\
& =\frac{(y+\alpha)(1+y+\alpha)}{(n-y+\beta)(1+n+\alpha+\beta)}\left[\frac{(y+\alpha)}{(n-y+\beta)}\right]^{2}, \\
& =\frac{(y+\alpha)(n-y+\alpha)}{(n-y+\beta)^{2}(1+n+\alpha+\beta)} .
\end{aligned}
$$

Dengan demikian berdasarkan Teorema Bayes maka penduga Bayes bagi $\theta$ adalah mean dari distribusi posterior yaitu

$$
\hat{\theta}^{B}=E(\hat{\theta} \mid y, \alpha, \beta)=\frac{(y+\hat{\alpha})}{(n+\hat{\alpha}+\hat{\beta})}
$$

dan ragam posterior bagi $\theta$ adalah

$$
\operatorname{Var}(\hat{\theta} \mid y, \hat{\alpha}, \hat{\beta})=\frac{(y+\hat{\alpha})(n-y+\hat{\beta})}{(n+\hat{\alpha}+\hat{\beta})(1+n+\hat{\alpha}+\hat{\beta})}
$$

\section{Langkah Penelitian}

Pada penelitian ini akan diduga angka pengangguran di kabupaten/kota di Sumatera Barat. Langkah-langkah yang dilakukan untuk mencapai tujuan dalam penelitian ini dijelaskan sebagai berikut:

(1) Menghitung dugaan langsung proporsi dan ragam proporsi pengangguran masing-masing kabupaten di Sumatera Barat dengan rumus:

$$
\hat{\theta}_{i}=\frac{y_{i}}{n_{i}} \operatorname{dan} \operatorname{Var}\left(\hat{\theta}_{i}\right)=\frac{\hat{\theta}_{i}\left(1-\hat{\theta}_{i}\right)}{n_{i}},
$$

dimana

$y_{i}=$ jumlah pengangguran di kabupaten/kota di Sumatera Barat,

$n_{i}=$ jumlah angkatan kerja di kabupaten/kota di Sumatera Barat,

$\hat{\theta}_{i}=$ dugaan langsung proporsi pengangguran kabupaten/kota di Sumatera Barat.

(2) Menghitung proporsi dan ragam proporsi pengangguran di Provinsi Sumatera Barat menggunakan rataan dan ragam terboboti dengan rumus:

$$
\hat{\theta}_{i}=\Sigma_{i=1}^{m}\left(\frac{n_{i}}{n_{t}}\right) \hat{\theta}_{i} \text { dan } s_{\theta}^{2}=\Sigma_{i=1}^{m}\left(\frac{n_{i}}{n_{t}}\right)\left(\hat{\theta}_{i}-\hat{\theta}\right)^{2}
$$


dimana

$\hat{\theta}=$ rataan terboboti proporsi pengangguran Provinsi Sumatera Barat,

$\hat{\theta}_{i}=$ dugaan langsung proporsi pengangguran kabupaten/kota di Sumatera Barat,

$m=$ jumlah kabupaten/kota di Sumatera Barat,

$n_{i}=$ jumlah angkatan kerja di kabupaten/kota di Sumatera Barat,

$n_{T}=\sum_{i=1}^{m} n_{i}$,

$s_{\theta}^{2}=$ ragam terboboti proporsi pengangguran Provinsi Sumatera Barat.

(3) Menduga parameter sebaran beta-binomial $\hat{\alpha}$ dan $\hat{\beta}$ dinyatakan dengan rumus berikut:

$$
\begin{aligned}
& \hat{\alpha}=\hat{\theta}\left[\frac{\hat{\theta}(1-\hat{\theta})\left[n_{T}-\sum_{i=1}^{m} n_{i}^{2}-(m-1)\right]}{n_{T} S_{\theta}^{2}-\hat{\theta}(1-\hat{\theta})(m-1)}-1\right], \\
& \hat{\beta}=\hat{\theta}\left[\frac{\hat{\theta}(1-\hat{\theta})\left[n_{T}-\Sigma_{i=1}^{m} n_{i}^{2}-(m-1)\right]}{n_{T} S_{\theta}^{2}-\hat{\theta}(1-\hat{\theta})(m-1)}-1\right]\left[\frac{1}{\hat{\theta}}-1\right]
\end{aligned}
$$

(4) Melakukan penduga EmpiricalBayes proporsi pengangguran $\hat{\theta}_{i}^{E B}$ masingmasing kabupaten di Provinsi Sumatera Barat menggunakan rumus:

$$
\hat{\theta}_{i}^{E B}=\hat{\gamma}_{i} \hat{\theta}_{i}+\left(1-\hat{\gamma}_{i}\right) \hat{\theta}
$$

dimana

$\hat{\gamma}_{i}=\frac{n_{i}}{n_{i}+\hat{\alpha}+\hat{\beta}}$

$\hat{\theta}_{i}=$ dugaan langsung proporsi pengangguran kabupaten di Sumatera Barat,

$\hat{\theta}=$ dugaan langsung proporsi pengangguran di Provinsi Sumatera Barat

(5) Membandingkan nilai standard error penduga langsung dengan penduga Empirical Bayes untuk mengevaluasi penduga dengan rumus

$$
S E\left(\hat{\theta}_{i}\right)=\sqrt{\frac{\operatorname{Var}\left(\hat{\theta}_{i}\right)}{n_{i}},}
$$

dimana

$S E\left(\hat{\theta}_{i}\right)=$ standard error penduga di kabupaten/kota di Sumatera Barat, $\operatorname{Var}\left(\hat{\theta}_{i}\right)=$ ragam penduga di kabupaten/kota di Sumatera Barat,

$n_{i}=$ jumlah angkatan kerja di kabupaten/kota di Sumatera Barat

\section{Hasil dan Pembahasan}

Pada Tabel 1 untuk Kabupaten Mentawai angka pengangguran pada penduga langsungnya adalah 0, 401 persen, nilainya hampir mendekati nol. Berarti di kabupaten tersebut hampir semua penduduk nya bekerja, padahal belum tentu di kabupaten tersebut jumlah penduduk pengangguran sangat sedikit, mungkin saja karena jumlah penduduknya sedikit sehingga memiliki nilai duga angka pengangguran yang sangat kecil. Sedangkan angka pengangguran tertinggi adalah wilayah Kota Padang 


\begin{tabular}{|c|c|c|c|c|c|}
\hline No & Kabupaten/Kota & $y_{i}$ & $n_{i}$ & Penduga Langsung $(\%)$ & StandardError $\left(\times 10^{-6}\right)$ \\
\hline 1 & Kepulauan Mentawai & 159 & 39610 & 0,401 & 1,596 \\
\hline 2 & Pesisir Selatan & 19097 & 173096 & 11,033 & 1,810 \\
\hline 3 & Kab.Solok & 8479 & 147474 & 5,749 & 1,578 \\
\hline 4 & Sijunjung & 3493 & 91716 & 3,808 & 2,087 \\
\hline 5 & Tanah Datar & 8707 & 175702 & 4,956 & 1,235 \\
\hline 6 & Padang Pariaman & 12296 & 167162 & 7,356 & 1,562 \\
\hline 7 & Agam & 11106 & 204408 & 5,433 & 1,080 \\
\hline 8 & Lima Puluh Kota & 7092 & 180126 & 3,937 & 0,969 \\
\hline 9 & Pasaman & 1976 & 127470 & 1,550 & 2,951 \\
\hline 10 & Solok Selatan & 2334 & 63672 & 3,666 & 2,183 \\
\hline 11 & Dharmasraya & 5331 & 101955 & 5,229 & 0,649 \\
\hline 12 & Pasaman Barat & 9685 & 149341 & 6,485 & 8,447 \\
\hline 13 & Padang & 52107 & 369641 & 14,097 & 8,525 \\
\hline 14 & Kota Solok & 1547 & 27349 & 5,657 & 11,275 \\
\hline 15 & Sawahlunto & 1737 & 28202 & 6,159 & 3,957 \\
\hline 16 & Padang Panjang & 1595 & 22679 & 7,033 & 4,452 \\
\hline 17 & Bukittinggi & 2529 & 53589 & 4,719 & 6,711 \\
\hline 18 & Payakumbuh & 4149 & 57919 & 7,163 & 6,069 \\
\hline 19 & Pariaman & 2159 & 35576 & & \\
\hline
\end{tabular}

Tabel 1. Hasil Perhitungan Dugaan Angka Pengangguran di Provinsi Sumatera Barat Metode Penduga Langsung

dengan nilai penduga langsung adalah14,097 persen. Nilai tersebut sangat tinggi karena angka pengangguran di Sumatera Barat adalah 6,39 persen. Angka pengangguran di Kota Padang dua kali lebih tinggi dari angka pengangguran di Sumatera Barat.

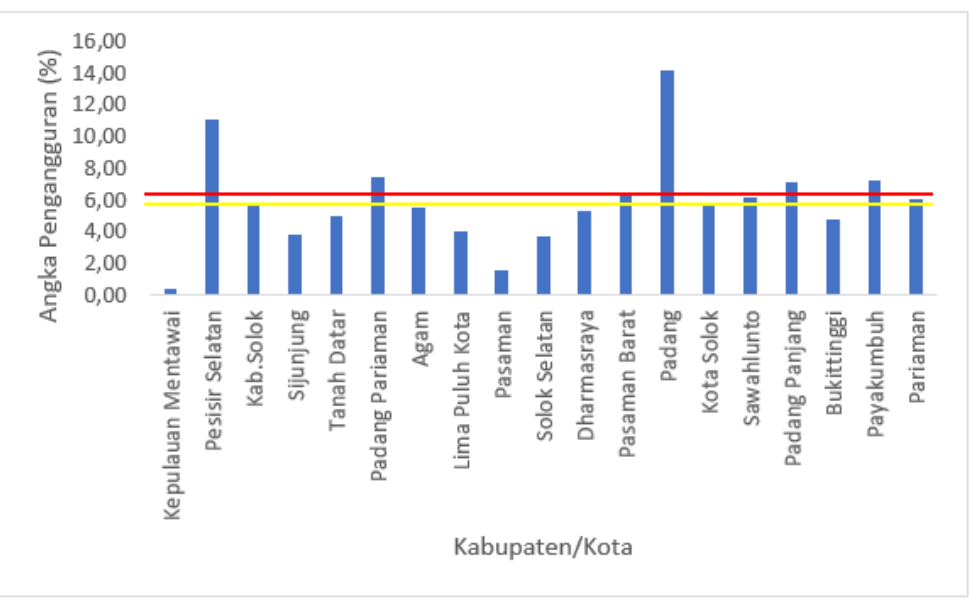

Gambar 1. Penduga Langsung Angka Pengangguran di Kabupaten/Kota di Sumatera Barat 


\begin{tabular}{|c|c|c|c|}
\hline No & Kabupaten/Kota & Penduga Empirical Bayes (\%) & Standard Error $\left(\times 10^{-6}\right)$ \\
\hline 1 & Kepulauan Mentawai & 0,408 & 1,609 \\
\hline 2 & Pesisir Selatan & 11,032 & 1,810 \\
\hline 3 & Kab.Solok & 5,750 & 1,578 \\
\hline 4 & Sijunjung & 3,810 & 2,087 \\
\hline 5 & Tanah Datar & 4,956 & 1,235 \\
\hline 6 & Padang Pariaman & 7,356 & 1,561 \\
\hline 7 & Agam & 5,434 & 1,109 \\
\hline 8 & Lima Puluh Kota & 3,938 & 1,080 \\
\hline 9 & Pasaman & 1,552 & 0,970 \\
\hline 10 & Solok Selatan & 3,668 & 2,951 \\
\hline 11 & Dharmasraya & 5,229 & 2,183 \\
\hline 12 & Pasaman Barat & 6,485 & 1,649 \\
\hline 13 & Padang & 14,096 & 0,941 \\
\hline 14 & Kota Solok & 5,659 & 8,44 \\
\hline 15 & Sawahlunto & 6,160 & 8,519 \\
\hline 16 & Padang Panjang & 7,033 & 11,265 \\
\hline 17 & Bukittinggi & 4,721 & 3,956 \\
\hline 18 & Payakumbuh & 7,163 & 4,451 \\
\hline 19 & Pariaman & 6,070 & 6,708 \\
\hline
\end{tabular}

Tabel 2. Hasil Perhitungan Dugaan Angka Pengangguran di Provinsi Sumatera Barat Metode EmpiricalBayes

Dari Tabel 2. terlihat bahwa angka pengangguran penduga langsung dan penduga Empirical Bayes berbasis model Beta-Binomial memberikan nilai dugaan yang tidak jauh berbeda, bahkan relatif sama. Untuk itu dilakukan evaluasi penduga menggunakan nilai standard error untuk melihat mana penduga terbaik.

Berdasarkan Tabel 3, hasil pendugaan angka pengangguran menggunakan model Small Area Estimation metode Empirical Bayes model Beta-Binomial mempunyai nilai standard error yang lebih kecil dibandingkan dengan pendugaan langsung. Sehingga dapat dikatakan bahwa metode Small Area Estimation metode Empirical Bayes model Beta-Binomial lebih baik daripada dengan pendugaan langsung.

\section{Kesimpulan}

Hasil pendugaan angka pengangguran di Sumatera Barat menggunakan metode penduga langsung dan penduga Empirical Bayes berbasis model Beta-Binomial memberikan nilai dugaan yang tidak jauh berbeda, bahkan relatif sama. Angka pengangguran terendah terdapat di Kabupaten Mentawai dan angka pengagguran tertinggi terdapat di Kota Padang dan Kabupaten Pesisir Selatan. Selebihnya angka pengagguran kabupaten/kota di Sumatera Barat berada sekitar nilai rata-rata pengangguran di Sumatera Barat.

Pendugaan angka pengangguran Metode Small Area Estimation dengan pendekatan Empirical Bayes berbasis model Beta-Binomial mempunyai nilai standard error yang lebih kecil dibandingkan dengan penduga langsung. Sehingga dapat dikatakan bahwa metode Small Area Estimation dengan pendekatan Empirical 


\begin{tabular}{|c|c|c|c|}
\hline No & Kabupaten/Kota & SE Penduga Langsung $\left(\times 10^{-6}\right)$ & SE Penduga Empirical Bayes $\left(\times 10^{-6}\right)$ \\
\hline 1 & Kepulauan Mentawai & 1,596 & 1,609 \\
\hline 2 & Pesisir Selatan & 1,810 & 1,810 \\
\hline 3 & Kab.Solok & 1,578 & 1,578 \\
\hline 4 & Sijunjung & 2,087 & 2,087 \\
\hline 5 & Tanah Datar & 1,235 & 1,235 \\
\hline 6 & Padang Pariaman & 1,562 & 1,561 \\
\hline 7 & Agam & 1,109 & 1,109 \\
\hline 8 & Lima Puluh Kota & 1,080 & 1,080 \\
\hline 9 & Pasaman & 0,969 & 0,970 \\
\hline 10 & Solok Selatan & 2,951 & 2,951 \\
\hline 11 & Dharmasraya & 2,183 & 2,183 \\
\hline 12 & Pasaman Barat & 1,649 & 1,649 \\
\hline 13 & Padang & 0,941 & 0,941 \\
\hline 14 & Kota Solok & 8,447 & 8,44 \\
\hline 15 & Sawahlunto & 8,525 & 8,519 \\
\hline 16 & Padang Panjang & 11,275 & 11,265 \\
\hline 17 & Bukittinggi & 3,957 & 3,956 \\
\hline 18 & Payakumbuh & 4,452 & 4,451 \\
\hline 19 & Pariaman & 6,711 & 6,708 \\
\hline
\end{tabular}

Tabel 3. Perbandingan Standard Error antara Penduga Langsung dengan Metode Empirical Bayes Model Beta-Binomial

Bayes berbasis model Beta-Binomial lebih baik daripada pendugaan langsung.

\section{Ucapan Terima kasih}

Penulis mengucapkan terima kasih kepada Ibu Dr. Maiyastri, Bapak Yudiantri Asdi, M.Sc, dan Bapak Zulakmal, M.Si yang telah memberi masukan dan saran sehingga malakah ini dapat diselesaikan dengan baik, serta pihak-pihak yang telah membantu dalam penulisan makalah ini.

\section{Daftar Pustaka}

[1] Bain, L.J. and M. Engelhardt. 1291. Introduction to Probability and Mathematical Statistic, Second Edition. Duxbury Press, California.

[2] Kismiantini. 2010. Penerapan Metode Bayes Empirik pada Penduga Area Kecil untuk Kasus Biner. Seminar Nasional Penelitian, Pendidikan dan Penerapan MIPA. Makalah. Jurusan Matematika FMIPA Universitas Negeri Yogyakarta.

[3] Walpole, R.E dan R.H. Myers. 1995. Ilmu Peluang dan Statistika untuk Insinyur dan Ilmuwan. Edisi Keempat. ITB, Bandung. 